\title{
Leitura estilística de um soneto da Fênix Renascida
}

Thiago Saltarelli

$\mathcal{L}$

Universidade Federal de Minas Gerais/CNPq

eia-se o seguinte soneto:

Esse baixel nas praias derrotado, Foi nas ondas Narciso presumido;

Esse farol nos céus escurecido,

Foi no monte libré, gala no prado;

Esse nácar em cinzas desatado,

Foi vistoso pavão de abril florido;

Esse Estio em Vesúvios incendido,

Foi Zéfiro suave em doce prado.

Se a nau, o Sol, a rosa, a Primavera,

Estrago, eclipse, cinza, ardor cruel

Sentem nos auges de um alento vago,

Olha, cego mortal, e considera

Que és rosa, Primavera, Sol, baixel,

Para ser cinza, eclipse, incêndio, estrago. ${ }^{1}$

${ }^{1}$ Citado a partir de RAMOS. Poesia barroca: antologia, [s.d.], p. 17. Na segunda edição da Fênix Renascida, de 1746 (disponível em versão digitalizada no site da Biblioteca Nacional de Portugal), o oitavo verso registra agrado em vez de prado: "Foi Zéfiro suave em doce agrado". 
Atribuído a Francisco de Vasconcelos, ele consta do terceiro tomo do cancioneiro português de poemas seiscentistas Fênix Renascida. Nele o poeta discorre sobre a fragilidade da vida humana, sujeita à fugacidade do tempo que a conduz inexoravelmente à morte. Os quartetos são constituídos por quatro períodos simples - dois em cada estrofe-que apresentam elementos da natureza ou do artifício humano em duas situações temporais diversas e contrastantes, a saber, o passado e o presente. Enquanto aquele foi glorioso, este não passa de um tempo de decadência e finitude. O termo gramatical que instaura essa diferença é o verbo de ligação ser, aqui utilizado no pretérito perfeito. Assim, tem-se que o baixel (produto do artifício humano), o sol, a rosa e a estação do ano (elementos da natureza), todos metáforas da vida humana, são caracterizados no presente, respectivamente, como derrotado, escurecido, desatada em cinzas e estio incendido em Vesúvios. Todos esses elementos ocupam a posição sintática de sujeito de seus respectivos períodos, aparecendo sempre nos versos ímpares dos quartetos, antes do verbo foi. Este, nos mesmos quartetos, inicia todos os versos pares, anunciando no predicado a condição passada gloriosa dos elementos metafóricos arrolados acima. Eles foram, respectivamente, Narciso presumido nas ondas, libré no monte ou gala no prado, pavão vistoso de abril florido e Zéfiro suave. Essa análise estritamente gramatical que se acabou de fazer dos quartetos revela uma profunda coerência na organização do discurso, uma forma de se ordenarem os versos a qual Dámaso Alonso denominou ordenação paralelística. ${ }^{2}$ Isso significa que entre os elementos de cada verso existe uma correlação de mesma função sintática, fazendo com que todos eles possuam a mesma estrutura. No caso do soneto que

\footnotetext{
${ }^{2} \mathrm{Cf}$. ALONSO. Táticas dos conjuntos semelhantes na expressão literária, p. 317-340.
} 
estamos analisando, as correlações são as seguintes ${ }^{3}$ (para uma melhor apreensão, apresentaremos os elementos desfazendo os hipérbatos, transferindo-os para a ordem canônica da oração em língua portuguesa):

Esse baixel /derrotado/ nas praias foi / Narciso presumido / nas ondas
(A1)
(B1)
/
(C1)
/

Esse farol /escurecido/ nos céus foi /libré/ no monte, /gala/ no prado ${ }^{4}$
(A2) /
(B2)
/ (C2)/
$/(\mathrm{C} 2) /$

Esse nácar /desatado em cinzas/ foi / pavão vistoso/ de abril florido (A3) /

(B3)

(C3)

Esse Estio/ incendido em Vesúvios / foi /Zéfiro suave/ em doce prado (A4) /

Assim, em todas as orações ou versos o elemento A ocupa a posição de sujeito, enquanto o elemento B designa o adjunto adnominal que determina esse sujeito e o elemento $C$ diz respeito ao predicativo que informa a condição passada do objeto ou fenômeno que constitui o sujeito da oração. Há que se ressaltar dois pontos: em primeiro lugar, esses elementos A, $B$ e $C$ ocorrem sempre na mesma ordem em todos os quatro grupos de versos que formam cada período. Além disso, não

3 Em cada uma dessas orações constituídas a partir do desmembramento dos versos, optamos por trabalhar apenas com as correlações entre o sujeito, seu determinante (os particípios passados com função adjetiva) e o predicativo. Podem-se encontrar correlações entre outros termos, como os adjuntos adnominais do predicativo (p.ex., presumido ou vistoso), os adjuntos adverbiais (p.ex., nas praias, nos céus), etc. Entretanto, em nossa análise essas correlações não são essenciais à demonstração do paralelismo dos versos.

${ }^{4}$ Classificamos os dois predicativos desse período - libré e gala como C2 justamente porque ambos pertencem ao mesmo período, são duas metáforas diversas para o mesmo elemento - o farol escurecido. 
somente eles, mas também os outros termos da oração (o verbo, os adjuntos adverbiais, etc) encontram-se na mesma ordem, daí surgind o o paralelismo perfeito dos versos. Em segundo lugar, esses elementos se encadeiam, em cada verso, por meio de sintagmas progressivos, um subordinado ao outro. Antes de surgir a segunda seqüência de metáforas, que compõe uma nova oração, a oração anterior já está terminada e completa. Por isso se diz que essa ordenação paralelística possui um caráter hipotático.

Diferentemente, no primeiro terceto, os elementos A1, A2, A 3 e $\mathrm{A} 4^{5}$ - que representam, como vimos anteriormente, os objetos ou fenômenos naturais ou artificiais sujeitos a um processo de decadência - são retomados juntamente com a conseqüência de sua derrocada, mas agora organizados, em cada verso, de maneira coordenada, em sintagmas não progressivos. O nono verso do poema traz esses elementos enumerados lado a lado, enquanto o décimo verso apresenta as conseqüências da decadência também enumeradas lado a lado. A ordenação dos conjuntos de conceitos em cada verso já não é mais hipotática, porém paratática, deixando de ser paralelística para se tornar correlativa. ${ }^{6}$ Interessante é notar,

${ }^{5} \mathrm{O}$ elemento A4 aparece no segundo quarteto como Estio, ao passo que em sua retomada no primeiro terceto surge como Primavera. Para nós, no entanto, o que importa aqui é o seu conteúdo conceitual genérico, designando as estações do ano que mudam por natureza. A primavera, no poema, seria o estado passado da vida humana, encontrando-se esta no auge de seu esplendor, enquanto o estio representa justamente sua decadência, pelo incêndio que provoca. Para uma definição de conteúdo conceitual genérico, cf. ALONSO. Táticas dos conjuntos semelhantes na expressão literária, p. 322 e 323.

${ }^{6}$ Trata-se ainda de terminologia utilizada por Dámaso Alonso, no mesmo texto referido na nota acima. 
todavia, observando-se o nono e o décimo versos do soneto, que a respectiva conseqüência da decadência de cada elemento encontra-se logo abaixo deste, inclusive visualmente:

Se a nau, o Sol, a rosa, a Primavera

Estrago, eclipse, cinza, ardor cruel

Assim, nau se relaciona com estrago; o sol se relaciona com o eclipse; a rosa tem como conseqüência transformar-se em cinza; e a primavera, por sua vez, torna em ardor cruel ou em estio. Esses conjuntos de expressões, completados pelo verbo sentir presente no décimo primeiro verso, permitem também uma leitura hipotática desse terceto, que encerra uma única oração adverbial condicional. Ter-se-ia então:

$>$ [Se] A nau sente [nos auges de um alento vago] estrago.

$>$ [Se] O Sol sente [nos auges de um alento vago] eclipse.

$>$ [Se] A rosa sente [nos auges de um alento vago] cinza.

$>$ [Se] A Primavera sente [nos auges de um alento vago] ardor cruel.

Essa dupla possibilidade de leitura - paratática e hipotática - é típica dos jogos de construção presentes na dispositio retórica dos poemas seiscentistas, que buscam um rebuscamento não apenas nas metáforas preciosas e no desenvolvimento de raciocínios engenhosos, mas na própria organização sintática e mesmo visual da obra. Ela está presente em outros poemas da Fênix Renascida e do Postilhão de Apolo, nos poetas do Siglo de Oro espanhol, em Gregório de Matos, em Manuel Botelho de Oliveira. Alguns sonetos chegam a apresentar esse tipo de correlação em todos os seus versos, constituídos cada um por sintagmas paratáticos que se relacionam hipotaticamente com todos os outros treze sintagmas que ocupam a mesma posição nos demais versos. Veja-se, como exemplo, este soneto de Botelho de Oliveira: 
Solicita, procura, reconhece, com desvelo, com ânsia, com ventura, sem temor, sem soberba, sem loucura, a quem ama, a quem crê, por quem padece.

Ajoelha-se, chora, se enternece, com pranto, com afeto, com ternura, e se foi indiscreta, falsa, impura, despe o mal, veste a graça, o bem conhece.

A seu Mestre, a seu Deus, a seu querido, rega os pés, ais derrama, geme logo, sem melindre, sem medo, sem sentido.

Por assombro, por fé, por desafogo, nos seus olhos, na boca, no gemido, água brota, ar respira, exala fogo.?

Tomando os sintagmas que ocupam a primeira posição de cada verso, teríamos a seguinte leitura hipotática: "Solicita, com desvelo [e] sem temor, a quem ama; ajoelha-se, com pranto, e se foi indiscreta, despe o mal; a seu Mestre rega os pés sem melindre; por assombro, nos seus olhos água brota". O mesmo encadeamento pode ser realizado com os demais sintagmas do poema.

Voltando a nosso soneto da Fênix Renascida, seu segundo terceto apresenta essa mesma ordenação com a dupla possibilidade de leitura, porém é um pouco mais complexo. Enquanto o primeiro terceto se constitui de apenas uma oração condicional, no segundo terceto há quatro orações. As duas primeiras, presentes no primeiro verso, são formadas por verbos no imperativo e expressam conselhos a quem o poeta se dirige. Esse ser finalmente aparece por meio do vocativo cego mortal, ou seja, é o homem, o ser humano que permanece cego para a condição frágil e finita de sua vida. Os conselhos vêm expressos pelos verbos olhar e considerar, e aí entra o segundo

${ }^{7}$ OLIVEIRA. Poesia completa (Lira Sacra), p. 311-312. 
verso, constituindo-se no objeto direto oracional desse último verbo. Isso significa que o ser humano deve considerar que ele é nau, sol, rosa e primavera. Aqui se tem mais uma vez a retomada dos elementos A1, A2, A3 e A4, porém não mais na ordem em que foram apresentados nos quartetos, como ocorrera no primeiro terceto. Da mesma forma, na oração subordinada adverbial que se encerra no último terceto, as conseqüências da passagem do tempo sobre aqueles elementos são novamente arroladas, também com uma pequena inversão que não houvera no primeiro terceto. Agora, a palavra primavera encontra-se sobre eclipse enquanto sol vem escrita sobre incêndio. Há assim um quiasma entre esses quatro termos na visualização hipotática dos dois últimos versos do poema.

Um último aspecto que deve ser comentado, sobre a ordenação dos versos e a organização do discurso do poema, é a reapresentação dos elementos A1, A2, A3 e A4 espalhados ao longo dos quartetos no nono verso do poema e, posteriormente, no décimo terceiro verso. Esse procedimento reiterativo, em que diversos elementos são disseminados ao largo de várias estrofes para posteriormente serem recolhidos no final do poema, geralmente num único verso, foi denominado por Dámaso Alonso de disseminativo-recoletivo, ou simplesmente disseminação e recolha. ${ }^{8}$ Em suas palavras, "não há tipo mais fértil em nossa literatura; aos montões (do mesmo modo que em sonetos, em canções, romances etc.) no-lo oferece Lope de Vega, e conhecidíssimo do público é este tipo, em infinitas florescências líricas do teatro de Calderón..." ${ }^{\prime 9}$. Da mesma forma

${ }^{8}$ ALONSO. Tática dos conjuntos semelhantes na expressão literária, p. 326-327. Algumas vezes encontra-se a variação semeadura e colheita para designar o mesmo procedimento.

${ }^{9}$ ALONSO. Tática dos conjuntos semelhantes na expressão literária, p. 327. 
que na literatura espanhola, esse procedimento também é recorrente na literatura de língua portuguesa do século XVII. ${ }^{10}$

Todo o nosso percurso até aqui, baseado, sobretudo, numa exaustiva análise lingüística do soneto de Francisco de Vasconcelos, procurou demonstrar como a ordenação dos conjuntos (expressão lógica e gramatical dos fenômenos) semelhantes no texto literário revela uma determinada organização do pensamento. No caso do soneto analisado, vê-se um raciocínio lógico de causa e efeito nos tercetos - o tempo causa a decadência da vida humana - ao mesmo tempo que um raciocínio analógico nos quartetos, em que quatro metáforas análogas servem de representação à frágil condição humana. Juntamente com o esmero da linguagem para a exposição das considerações do poeta, a dupla possibilidade da leitura paratática e hipotática dos tercetos desvela um aspecto presente na construção da poesia seiscentista que alguns estudiosos tradicionais do Barroco consideram como lúdico. Ainda nos fazendo acompanhar do pensamento de Dámaso Alonso, poderse-ia dizer que trabalhamos até agora com a dimensão conceitual da obra literária, aquela que privilegia o aspecto lógico do texto, em que o estilo reflete uma forma de pensamento. ${ }^{11}$

Ao lado desse aspecto, há um outro responsável por suscitar no leitor representações imagéticas sensoriais, e por

\footnotetext{
${ }^{10}$ Isso se dá não apenas pelo fato de a Península Ibérica, apesar das constantes guerras entre seus diversos reinos, partilhar características culturais comuns, desde a Idade Média - e sobremaneira no século XVII, quando a coroa portuguesa esteve anexada à coroa castelhana sob o reino dos Filipes - mas também porque, a partir de uma matriz retórica comum e da ideia de emulação de modelos, as literaturas românicas em geral, nesse período, servem-se dos mesmos códigos retórico-poéticos nos procedimentos da inventio, da dispositio e da elocutio na poesia.

${ }^{11}$ Cf. ALONSO. Poesia espanhola, p. 363-372.
} 
isso mesmo denominado imaginativo. ${ }^{12}$ Algumas vezes encontrase a variação semeadura e colheita para designar o mesmo procedimento.

Essas imagens, que podem ser de ordem visual, auditiva, olfativa, táctil, etc, são suscitadas pelo recurso a elementos que estão na esfera do significante (como ritmo, enjambement, aliterações, sinalefas, dentre outros) e do significado (figuras e tropos de palavras e pensamentos). ${ }^{13}$ No caso específico do soneto aqui analisado, as imagens são oriundas sobretudo dessa última esfera, produzidas pelas abundantes metáforas espalhadas pelo poema. Como se disse mais acima, o soneto contém quatro elementos, produtos da natureza ou do engenho humano, que metaforizam a condição humana. Logo, esta se apresenta sob as imagens de barco ou navio, sol, rosa e estação do ano. A fim de adensar o campo imagético do poema e o rebuscamento figurativo, duas dessas metáforas, inicialmente, estão como que "ocultas" por perífrases, não sendo o termo de comparação com a fragilidade humana designado diretamente. Enquanto navio e estação do ano são designados diretamente pelas palavras baixel e Estio, o sol e a rosa estão contidos, respectivamente, nas perífrases farol [nos céus] e nácar. Interessante é notar, porém, que essas perífrases, bem como as metáforas, eram recorrentes no século XVII e mesmo antes disso, sendo conhecidas dos leitores da época, mais do que isso, compondo um código retórico relativamente rígido partilhado pelo público letrado. Tal característica assemelha-

${ }^{12}$ Cf. ALONSO. Poesia espanhola, p. 363-372.

${ }^{13}$ Cf. ALONSO. Poesia espanhola, p. 453-457. A discussão sobre as diversas e possíveis definições do que seja significante e significado - que também podem levar à questão da forma e do conteúdo ultrapassa as intenções do presente trabalho. Algumas definições e argumentos para essa questão são apresentados pelo próprio Dámaso Alonso na obra citada. 
se à hierarquia e à rigidez estamental daquele tempo, quando, assim como os estamentos sociais estavam fixados sem possibilidade de trânsito entre eles, o código retórico-poético e as regras de gênero textual também obedeciam a essa rigidez.

A metáfora da rosa simbolizando a passagem do tempo e a fragilidade da vida humana pode ser encontrada, por exemplo, num famoso soneto de Antônio da Fonseca Soares, tradicionalmente atribuído a Gregório de Matos: ${ }^{14}$

É a vaidade, Fábio, desta vida,

Rosa, que da manhã lisonjeada,

Púrpuras mil, com ambição dourada,

Airosa rompe, arrasta presumida.

É planta, que de abril favorecida,

Por mares de soberba desatada,

Florida galeota empavesada,

Sulca ufana, navega destemida.

É nau enfim, que em breve ligeireza

Com presunção de Fênix generosa,

Galhardias apresta, alentos preza:

Mas ser planta, ser rosa, nau vistosa

De que importa, se aguarda sem defesa

Penha a nau, ferro a planta, tarde a rosa? ${ }^{15}$

${ }^{14}$ Em sua edição crítica da obra de Gregório de Matos, Francisco Topa não considera esse soneto como sendo do autor e afirma que ele pertence "com toda certeza a Antônio da Fonseca Soares". Cf. TOPA. Edição crítica da obra poética de Gregório de Matos, v. II, anexo, p. 67-68, de onde transcrevemos o soneto.

${ }^{15}$ Esse soneto, na verdade, foi concebido sob o mesmo modelo conceitual e imaginativo daquele que estamos analisando. Trata do mesmo tema - o desengano da vida humana diante de sua fragilidade - e utiliza praticamente as mesmas metáforas e os mesmos processos de construção - a título de exemplo, observe-se o procedimento de disseminação e recolha. Isso vem ao encontro da idéia de que o século XVII, imbuído na poética clássica, 
Podemos ir mais além na tradição, buscando em Góngora, Marino, Shakespeare, Camões e Petrarca os motivos e metáforas a serem reutilizados. Observe-se novamente a metáfora da rosa neste outro soneto, de Ronsard:

Comme on voit sur la branche au mois de may la rose,

En sa belle jeunesse, en sa premiere fleur,

Rendre le ciel jaloux de sa vive couleur,

Quand l'Aube de ses pleurs au poinct du jour l'arrose;

La grace dans sa fueille, et l'amour se repose,

Embasmant les jardins et les arbres d'odeur;

Mais batue ou de pluye, ou d'excessive ardeur,

Languissante elle meurt, fueille à fueille déclose.

Ainsi en ta premiere et jeune nouveauté,

Quand la Terre et le Ciel honoroient ta beauté,

La Parque t'a tuee, et cendre tu reposes.

Pour obseques reçoy mes larmes et mes pleurs,

Ce vase plein de laict, ce panier plein de fleurs,

Afin que vif et mort ton corps ne soit que roses. ${ }^{16}$

Em ambos os sonetos transcritos, obedecendo ao código retórico-poético, a rosa é metáfora da vida humana e, portanto, a despeito de sua beleza, vivacidade e fragrância, sempre fenece. A mesma metáfora ainda pode ser encontrada nas oitavas "À rosa", de Botelho de Oliveira, e em dezenas de outros poemas da Fênix Renascida. Voltando, porém, ao soneto de Antônio da Fonseca, veremos que também há ali a metáfora da nau, como no de Francisco de Vasconcelos. Esta é outra metáfora largamente utilizada para representar a condição humana, especialmente em Portugal, que a partir do século XV

partilhava de um código retórico-poético fixo, que, não conhecendo a noção moderna de plágio, incentivava a imitação de modelos canonizados pela tradição.

16 RONSARD. Oeuvres complètes, p. 184. 
desenvolveu uma poderosa e marcante cultura marítima. Esse traço social será tão forte que contaminará a poesia desde os tempos do Renascimento até pelo menos o Modernismo de Fernando Pessoa. Uma grande fonte dessa metáfora, talvez a principal para a literatura portuguesa, é sem dúvida Os Lusíadas.

Assim como os elementos que representam a condição humana no presente são metafóricos, também o são aqueles que representam essa condição no passado, o que cria um jogo interessantíssimo de homologia entre figuras. Tomemos como exemplo a terceira metáfora, a da rosa, e sua contraparte - pavão vistoso de abril florido. A expressão vistoso pavão é uma metáfora que caracteriza a também metafórica e perifrástica nácar em cinzas desatado. Se essa última expressão é uma perífrase para a rosa, então pavão é metáfora de rosa. Mas acontece que a rosa também é metáfora, digamos, da vaidade humana - em última instância, do próprio homem. Então, pavão vistoso é metáfora da vaidade e por conseguinte do homem. O que acontece, entretanto, é que essa relação entre a palavra e a coisa não se dá diretamente, mas por homologia, deslizando de figura a figura. ${ }^{17} \mathrm{O}$ mesmo acontece na relação entre as outras metáforas do soneto. Essa atribuição de valor às palavras através do contraste ou da semelhança que elas estabelecem entre si dentro da obra literária, somada à rigidez do código retórico-poético, leva muitas vezes à cristalização de algumas metáforas que, por uma analogia engenhosa, criam uma identidade entre coisas diferentes e ganham uma espécie de valência para designar este ou aquele conceito especificamente. Essas metáforas, então, inserem-se no código retórico partilhado pelos autores e leitores da produção letrada, dispensando qualquer menção àquilo que elas de fato denotam, e passam a designar um conceito específico - ou mais de um, que estabelece uma identidade com o outro e varia conforme o contexto. Tem-se

${ }^{17}$ GENETTE. Figuras, p. 39. 
então que ouro, por exemplo, é metáfora de tudo o que apresente a propriedade de ser dourado, a saber: cabelos de mulher, azeite de oliveira, messes de trigo, mel de abelha, etc. ${ }^{18} \mathrm{E}$, por meio desse jogo figurativo, as messes de trigo podem se transformar na metáfora dos cabelos, o mel pode se tornar metáfora do azeite. Essas metáforas mineralizadas, que compõem o código poético dos Seiscentos, também foram buscadas, como as demais, na tradição. Já se pode ver em Camões o seu uso, que, como se disse, dispensa a menção à palavra denotada:

Ondados fios de ouro reluzente, Que, agora da mão bela recolhidos, Agora sobre as rosas estendidos, Fazeis que sua beleza se acrescente;

Honesto riso, que entre a mor fineza

De perlas e corais nasce e parece,

Se na alma em doces ecos não o ouvisse! ${ }^{19}$

No quarteto transcrito (que é o primeiro do soneto) a palavra ouro designa os cabelos e a palavra rosas designa as faces de uma mulher. Em momento algum o poeta citou as palavras cabelos e faces. Ao dizer que os fios de ouro encontram-se estendidos sobre as rosas, ele nada mais fez que afirmar que os cabelos se estendem sobre a face. No entanto, cabe ao leitor conhecedor do código poético fazer essa operação de decodificação. Da mesma forma, no terceto, afirma-se que o riso da mulher nasce de pérolas e corais. Essas palavras designam os dentes e a boca, esta supostamente de forte cor escarlate.

Este outro exemplo, retirado de Manuel Botelho de Oliveira, é muito interessante para ilustrar o que se disse mais acima sobre as metáforas cristalizadas. Aqui, também sem

${ }^{18}$ Cf. RAMOS. Poesia barroca: antologia.

${ }^{19}$ CAMÕES. Obra completa, p. 288. 
mencionar os objetos denotados, o poeta utiliza a mesma metáfora - cristal - para designar duas coisas aparentemente bem diversas: a água e o rosto da amada. É o raciocínio denominado de agudo, promovido pelo engenho, que permite criar uma identidade entre esses elementos a princípio tão distintos, com base em propriedades semelhantes entre eles, como o brilho, a luminosidade, a transparência e ao mesmo tempo a fluidez e a esquivança. Eis o poema:

A Serpe, que adornando várias cores,

Com passos mais oblíquos, que serenos,

Entre belos jardins, prados amenos,

É maio errante de torcidas flores;

Se quer matar da sede os desfavores,

Os cristais bebe co'a peçonha menos,

Porque não morra c'os mortais venenos,

Se acaso gosta dos vitais licores.

Assim também meu coração queixoso,

Na sede ardente do feliz cuidado

Bebe c'os olhos teu cristal fermoso;

Pois para não morrer no gosto amado,

Depõe logo o tormento venenoso,

Se acaso gosta o cristalino agrado. ${ }^{20}$ (grifo nosso)

No segundo quarteto, a serpe que bebe os cristais indica o ato de a serpente ingerir água. Já no primeiro terceto, é o poeta quem bebe, com os olhos, o cristal da amada, ou seja, sorve as belezas da sua face. O mesmo tipo de agudeza - esta metáfora culta que aproxima dessemelhantes pela perspicácia engenhosa do poeta - aplica-se à caracterização da serpente, definida como maio errante de torcidas flores. Ora, como um animal pode ser metaforizado como um mês do calendário? Naturalmente, a partir de propriedades semelhantes encontradas entre figuras

${ }^{20}$ OLIVEIRA. Poesia completa (Música do Parnasso), p. 23. 
intermediárias entre os dois conceitos extremos - serpe e maio obviamente não mencionadas no processo de criação da agudeza. Desvelando o procedimento, o deslizamento de figura a figura pode dar-se da seguinte forma:

Serpe $>$ escamas $>$ cores $>$ flores $>$ primavera $>$ Maio $($ no hemisfério norte)

Conforme a crítica estilística em geral, todas as imagens por nós levantadas até o presente momento refletiriam um traço da mentalidade do homem seiscentista - uma vez que o imaginativo e o conceitual (e também o afetivo) nunca se separam na realidade da obra literária. Elas mostram que esse homem, dito "barroco" por críticos tradicionais, organiza o mundo por paralelos e contrapostos, na tentativa de resumir as diversas gamas de diferenças entre as coisas a oposições, reduzindo o mundo que se apresenta difuso a um sistema de simetrias. Em contraste com a dispersão da realidade, encontra-se nessa sociedade um rígido código retórico-poético de produção artística, que não só auxilia na apreensão e encenação do mundo como também representa e desvela a própria força da hierarquia social. É preciso lembrar que o século XVII é o auge do Absolutismo, com seus estamentos sociais muito bem definidos. Em todo lugar e função se vê a fixidez de uma estrutura fortemente hierarquizada: na Igreja, no poder político, nas funções militares, nas universidades, nos espetáculos públicos, nas produções artísticas. Além disso, tratase de uma sociedade de aparências, bastante alegorizada, em que tudo é encenado e figurativizado, desde as festas populares até os ritos eclesiásticos. O mundo do século XVII, nas palavras de Calderón de la Barca, é um grande teatro, e a riqueza do código poético que, embora rígido, atinge esplendores de trabalho com a linguagem, reflete isso no plano literário. $\mathrm{O}$ mundo como teatro, que privilegia a organização do discurso por agudezas e metáforas, revela a riqueza da dimensão imaginativa da poesia seiscentista. 
Contudo, ao lado da hierarquia, do esplendor e da teatralidade, há também um grande senso da fugacidade do tempo, uma percepção muito forte do mundo e da vida como um lugar e um estado sujeitos sempre à mudança, no meio da qual o homem se encontra e pela qual, muitas vezes, ele se angustia. Como no soneto que analisamos, em diversos outros poemas dessa época surge essa temática, que, tamanha a recorrência, acaba por se transformar num tópos poético, o tempus fugit. No que concerne à dimensão afetiva do estilo da poesia do século XVII, diríamos que o desengano é um dos afetos dominantes. O homem se vê desenganado com relação a tudo: à beleza, à juventude, aos amores, às riquezas, enfim, a qualquer manifestação da vida terrena. Esse fato fornece mais uma possibilidade poética de jogos e trocadilhos, e os poetas constantemente associam o estado provisório das coisas provocado pela mudança com a constância com que ela ocorre, ou a instabilidade das coisas do mundo com a estabilidade da mudança. Daí surgem as antíteses, os paradoxos e os oxímoros entre a inconstância do mundo - porque este muda - e a constância com que ele muda - porque sempre muda. Essa percepção, aliada com a forte influência que o Cristianismo exerce sobre o homem e a sociedade desse século, torna vãs as coisas mundanas, uma vez que todas elas jamais serão perenes. Calderón de la Barca, em La vida es sueño, dá-nos a exata dimensão do que é a vida para um homem do século XVII:

\footnotetext{
¿Qué es la vida? Un frenesí.

¿Qué es la vida? Una ilusión,

Una sombra, una ficción,

Yel mayor bien es pequeño;

Que toda la vida es sueño,

Y los sueños, sueños son. ${ }^{21}$
}

${ }^{21}$ CALDERÓN DE LA BARCA. Obras completas, v.1, p. 243. 
O Cristianismo nunca deixa esquecer que o final desse percurso de mudanças da vida humana é a morte, contra a qual nenhum homem pode se impor. Neste ponto, chegamos às camadas mais externas do círculo filológico de nossa análise estilística do soneto de Francisco de Vasconcelos, aquelas em que nos distanciamos do pormenor para observar o todo do poema em relação com seu ambiente histórico e cultural. A organização linguístico-literária do soneto e suas dimensões conceitual, imaginativa e afetiva coadunam-se com a mentalidade que perpassa a retórica, a política e a teologia seiscentistas. No limite, o estilo, no poema em questão, põe-se a serviço da representação da condição humana como pura fragilidade. A vida, afinal, é emprestado estado, como afirma, num outro soneto, Gregório de Matos...

\section{Referências bibliográficas e bibliografia de apoio}

ALONSO, Dámaso. Poesia espanhola: ensaios de métodos e limites estilísticos. Trad. Darcy Damasceno. São Paulo: Instituto Nacional do Livro, 1960.

ALONSO, Dámaso. Táticas dos conjuntos semelhantes na expressão literária. In: LIMA, Luiz Costa. Teoria da literatura em suas fontes. Rio de Janeiro: Civilização Brasileira, 2002. v.1, p. 317-340.

AUERBACH, Erich. L'humaine condition. In: AUERBACH, Erich. Mimesis. São Paulo: Perspectiva, 2002, p. 249-276.

CALDERÓN DE LA BARCA, Pedro. Obras completas. Madrid: Aguilar, 1951. v.1.

CAMÕES, Luís de. Obras completas. Rio de Janeiro: Aguilar, 1963.

A Fenix Renascida, ou obras poeticas dos melhores engenhos portuguezes. Segunda vez impresso e accrescentado por Mathias Pereira da Sylva. Lisboa: Officina dos Herdeiros de Antonio Pedrozo Galram, 1746.

GENETTE, Gérard. Figuras. São Paulo: Perspectiva, 1972. 
GOMES, João Carlos Teixeira. Gregório de Matos, o boca de brasa. Petrópolis: Vozes, 1985.

HANSEN, João Adolfo. Barroco, neobarroco e outras ruínas. In: Teresa, revista de literatura brasileira, São Paulo, Ed. 34, 2001, p. 10-66.

LATERZA FILHO, Moacyr. A ópera dos afetos: para uma intertextualidade das paixões: leitura comparativa das retóricas do Padre Antônio Vieira e do Padre Antonio Vivaldi. 2003. Tese (Doutorado em Letras) - Faculdade de Letras, Pontifícia Universidade Católica de Minas Gerais, Belo Horizonte.

LEÃO, Ângela Vaz. Sobre a estilística de Spitzer. Belo Horizonte: Universidade de Minas Gerais, 1960.

OLIVEIRA, Manuel Botelho de. Música do Parnaso. Cotia: Ateliê Editorial, 2005. edição fac-similar.

OLIVEIRA, Manuel Botelho de. Poesia completa: Música do Parnasso - Lira Sacra. Introdução, organização e fixação de texto de Adma Muhana. São Paulo: Martins Fontes, 2005.

RAMOS, Péricles Eugênio da Silva. Poesia barroca: antologia. [s.1.]: Melhoramentos, [s.d.].

RONSARD, Pierre de. Oeuvres complètes. Abeville: Gallimard, 1950. v.1.

SPINA, Segismundo. História da língua portuguesa III - segunda metade do século XVI e século XVII. São Paulo: Ática, 1987.

SPITZER, Leo. A Poesía española de Dámaso Alonso. In: LIMA, Luiz Costa. Teoria da literatura em suas fontes. Rio de Janeiro: Civilização Brasileira, 2002. v.1, p. 377-408.

TEIXEIRA, Ivan. A poesia aguda do engenhoso fidalgo Manuel Botelho de Oliveira. In: OLIVEIRA, Manuel Botelho de. Música do Parnaso. Cotia: Ateliê Editorial, 2005. edição fac-similar.

TOPA, Francisco. Edição crítica da obra poética de Gregório de Matos. Porto: Edição do Autor, 1999. v. II: Edição dos sonetos; anexo Sonetos excluídos. 
VOSSLER, Karl; SPITZER, Leo; HATZFELD, Helmut. Introducción a la estilística romance. Introducción y notas de Amado Alonso y Raimundo Lida, $2^{a}$ ed. Buenos Aires: [s.n.], 1942.

\section{Resumo}

Neste trabalho, homenagem ao nonagésimo aniversário da professora Ângela Vaz Leão, empreendemos uma leitura estilística de um soneto da Fênix Renascida, principal cancioneiro da poesia seiscentista portuguesa. A partir da metodologia do círculo filológico, proposta por Leo Spitzer, pela qual se realiza uma contínua passagem das partes ao todo e do todo às partes do texto, procedemos a uma exaustiva análise dos elementos linguísticos do poema, procurando ressaltar seus aspectos conceituais, imaginativos e afetivos, segundo a doutrina de Dámaso Alonso, não, contudo, para ter acesso à personalidade ou delinear o psiquismo do autor, senão para, em consonância mais com as ideias de Karl Vossler, agregar à interpretação elementos das mentalidades e do contexto histórico-cultural do poema. Ao empregar o método estilístico, tão caro à profa. Ângela, visamos à emulação de sua práxis analítica, acreditando assim render-lhe justa homenagem.

\section{Resumen}

En este trabajo, homenaje al nonagésimo cumpleaños de la profesora Ângela Vaz Leão, emprendemos una lectura estilística de un soneto de la Fênix Renascida, principal cancionero de la poesía portuguesa del siglo XVII. A partir de la metodología del círculo filológico propuesta por Leo Spitzer, por la cual se realiza un paso continuo desde las partes al todo y desde el todo a las partes del texto, 
procedemos a un exhaustivo análisis de los elementos lingüísticos del poema, procurando resaltar sus aspectos conceptuales, imaginativos y afectivos, según la doctrina de Dámaso Alonso, no, sin embargo, para tener acceso a la personalidad o delinear el psiquismo del autor, sino para, en consonancia más con las ideas de Karl Vossler, agregar a la interpretación elementos de las mentalidades y del contexto histórico-cultural del poema. Al emplear el método estilístico, tan estimado por la profa. Ângela, buscamos emular su práxis analítica, creyendo así rendirle justo homenaje. 